\title{
Calculation of Open Water Evaporation as a Climate Parameter
}

\author{
Nabil H. Swedan \\ Pacific Engineering PLLC, Olympia, WA, USA \\ Email: nabilswedan2@gmail.com, swedan@pacificengineeringpllc.com
}

How to cite this paper: Swedan, N.H. (2018) Calculation of Open Water Evaporation as a Climate Parameter. Journal of Water Resource and Protection, 10, 762-779. https://doi.org/10.4236/jwarp.2018.108043

Received: July 14, 2018

Accepted: August 14, 2018

Published: August 17, 2018

Copyright $\odot 2018$ by author and Scientific Research Publishing Inc. This work is licensed under the Creative Commons Attribution International License (CC BY 4.0).

http://creativecommons.org/licenses/by/4.0/

\begin{abstract}
Calculation of open water evaporation is important for hydrology, industry, agriculture, environment, and other fields. The available methods of calculating evaporation are based on field or laboratory experiments and should not be used for scale-up to open water evaporation for similitude relationships cannot be correctly obtained. The methods are thus unjustified scientifically. In addition, surface evaporation is not a local phenomenon that is a function of independent meteorological parameters. These are in fact dependent parameters, and the solar energy exchanged with the surface of the earth is the only independent variable for open water evaporation. Contrary to the existing methods, meteorological records and measurements are therefore not required. Many parts of the world do not have full or partial records available. For these, the available methods are likely not to be useful. In addition, future meteorological records or measurements cannot be made available for evaporation projection in a warming world. This may well place a limit on using the existing methods. The work presented in this manuscript reveals a new understanding of evaporation as a climate parameter instead and can be calculated as such. Minimal to no meteorological records or measurements may be required. The advantages of the proposed method are scientific justification, simplicity, accuracy, versatility, low to virtually no cost, and can be used to map present and future evaporation in a short period of time.
\end{abstract}

\section{Keywords}

Evaporation, Thermodynamics, Beer-Lambert Law, Optical Depth

\section{Introduction}

Evaporation applications by solar energy are characterized by low cost, and solar evaporation pans have been used to produce salt, minerals, and chemicals for a 
long time [1] [2]. Waste streams are collected and evaporated in ponds for zero discharge applications [3] [4]. They are increasingly desirable to meet environmental requirements. Pond and reservoir utilization is not limited to industry; they are used for irrigation, farming, recreational, and other purposes. Artificial lakes and lagoons are created following dam construction, and ponds are built for fish farms, waste water treatment, and farm drainage collection [5]. Open water evaporation is a key design parameter for most of these applications and therefore merits consideration. In addition, open water evaporation can be used to calculate evapotranspiration and crop irrigation [6].

The importance of determining present and future evaporation and the time and costs required for preparing meteorological records motivated this submission. Open water evaporation is not the same as class A or test pan evaporation. While these vary with local ambient conditions, open water evaporation is a climate parameter. It varies with the solar energy exchanged with the surface of the earth as this work indicates. Its variability during the year is caused mostly by variation in the earth's axial tilt with the motion of the earth around the sun. This motion is an established knowledge and can be used as basis for evaporation calculation. Because world average surface temperature and evaporation are measured, they can be used as pilot data. The latitude at which the world average values manifest can be determined. Similitude relationships can then be established between the latitudes, and open water evaporation can be scaled-up and obtained. Minimal to no meteorological variables are necessary. Scale-up from laboratory and pilot data are scientific methodologies widely used in the chemical and other industries.

The objective of this manuscript is to derive the equation of open water evaporation utilizing the physics of the earth and scale-up methodologies, calculate evaporation for sample locations, and compare the calculated evaporation with observations. The calculated evaporation is found to be in agreement with observations. This offers an inexpensive way of mapping present and future evaporation cost effectively in a short period of time, which has merit at the societal level.

\section{Background Information}

Reference [6] presented Food and Agriculture Organization (FAO) paper No. 56. The paper addresses among other subjects calculation of evapotranspiration and evaporation from open water. These are important parameters for crop irrigation, hydrology, and environmental considerations. Empirical equations and pan evaporation methods are explained. The hurdles and uncertainties with the procedures are highlighted in the paper. Reliable meteorological records are necessary, which require time and considerable expenditure. Publication [7] derived a formula based on energy and dynamic considerations, which is widely used for calculating local evaporation. A similar approach was adopted by [8] for larger water bodies. Numerous papers have been written to calculate evaporation 
using empirical equations. References [6] [9] present applications of typically considered equations. These and similar methods require meteorological records for calculating evaporation, which include solar radiation, air temperature, humidity, and wind speed. Not every part of the world can afford to produce the required meteorological data. Publication [10] explains the difficulty associated with using empirical formulas to calculate evaporation in the Sahel and neighboring countries which lack climate data. Meteorological records could be incomplete or erratic. Another method of calculating evaporation discussed in FAO paper No. 56 is the use of evaporation pans. This method presents uncertainty in estimating the pan coefficient for scale-up to open water evaporation. The value of pan coefficient varies between 0.35 and 0.85 , depending on wind speed, presence of vegetation, pan setting, and other weather and climate variables. Factor assessment thus requires climate records and experience.

Meteorological stations use class A evaporation or equivalent pan. In the industry, it is common to install larger-diameter test evaporation pans having two meters in diameter and approximately $60 \mathrm{~cm}$ deep. For these pans, the recommended coefficient for scale-up to open water evaporation is between 0.6 and 0.7 [11] although a coefficient of 0.8 and slightly higher is proposed [12]. One reason for these uncertainties is that class A and test pans have a small mass of liquid compared with actual water bodies. They are either above ground or buried just below the surface, and similarity for scale-up to open water evaporation is not satisfied. Unlike larger water bodies, class A or test pans are impacted considerably by the variability of ambient and surrounding ground temperatures readily. Weather elements, water turbidity, algae growth, and wild life are a partial list of causes that adversely impact readings of pan evaporation.

The calculated evaporation or factors are valid for the specific site or location in consideration, which renders these methods expensive and impractical for mapping evaporation, especially in a warming world. Reference [13] presents other available methods. These include mass balance, energy budget models, combination models, equilibrium temperature, and empirical factors. All of these methods require measurements and meteorological records as well. The final equations and factors derived apply for the specific water body or site where the measurements are made. The equations and factors are not transferable to other water bodies or locations. It is not uncommon to obtain a significant difference in the calculated evaporation between one method and another [14] [15]. For these reasons, the calculated evaporation in this work will be compared with actually measured or observed evaporation. Measuring evaporation with accuracy requires experienced professionals. For instance, water body mass balance is an involved task and presents uncertainties associated with water supply and discharge streams. These include rivers, creeks, precipitation, surface runoffs, ground water inflow, underground leakage, and others. Typically, comprehensive and expensive studies are conducted for this purpose.

Clearly, the existing methods assume that evaporation as a mathematical 
function and the meteorological parameters as independent parameters of the function. This may be true for cooling towers and other industrial applications but not for surface evaporation of the earth. Evaporation is a heat transfer phenomenon, and in the absence of variation in the heat exchanged with the surface, surface evaporation remains unchanged regardless of the values of wind speed, relative humidity, or surface temperature. In reality, evaporation and the meteorological parameters are dependent parameters; they depend on the heat exchanged with the surface, which is the only independent parameter. This heat exchanged varies with the motion of the earth around the sun. Because the motion of the earth is known, meteorological record is not required for calculating surface evaporation.

Unlike the existing methods, open water evaporation is calculated by knowing the physics of the earth and the available data relative to world average surface temperature and evaporation. These can be used as pilot data. The scale-up from laboratory and pilot data using similitude is a scientific method that is widely used for complex applications. Most of the commercial complexes presently operating in the world have been designed based on scale-up procedures. Chemical engineering reference [16] present detailed explanations of the different methods used. Dimensionless groups of parameters are derived that apply for the pilot and the commercial units based on the laws of conservation of mass and energy at steady state operation. Mathematical expressions are formulated in accordance with the laws of physics governing the phenomenon being considered. For open water evaporation, the measured precipitation and surface temperature by researchers over the years are pilot data and can be used for scale-up from one latitude to another. A scale-up relationship for latitude evaporation with respect to the world average evaporation is then derived. The advantage of this scale-up methodology is that it is representative because it is between earth subsystems and similarity exists. The procedure thus adheres to the scientific methodologies. This is not the case for the existing methods that have been developed based on small laboratory or field experiments. The earth cannot be tested in laboratory or engineering setting, and similitude between these experiments and the earth does not exist. The existing procedures are thus incorrect, and using the current methods of calculating evaporation in climate models or other evaporation calculation products is not supported by science. The proposed method in this work on the other hand is scientifically justified and yields good values of open water evaporation.

\section{Data}

Evaporation data for validation are gathered to subject the proposed procedure to a vigorous test. Sample locations of the world have been selected such that they have considerably different geographic and climatic conditions. The Dead Sea, $31^{\circ} \mathrm{N}$, Jordan, is the lowest location on the surface. The related evaporation is obtained from an engineering study conducted by [12]. The measured read- 
ings of the test evaporation pans are not adjusted for rainfall. Therefore, rainfall data are added to obtain actual evaporation. Data for Lake IJssel, Netherland, are part of a study report prepared by [17] for the Royal Netherlands Meteorological Institute. This lake is next to the Atlantic Ocean at about $52^{\circ} \mathrm{N}$. For Melbourne, Australia, $37.5^{\circ} \mathrm{S}$ at about sea level, evaporation is available at the Australian Government Bureau of Meteorology website. Lake Okanagan is located in south west Canada, $49.5^{\circ} \mathrm{N}$ at roughly $350 \mathrm{~m}$ above sea level. The surface of this lake freezes during most of winter. Class A pan evaporation data are provided by [14] Environment Canada, Water Science and Technology Directorate. A good source of class A pan evaporation is the Western Climate Regional Center website. As discussed in the Introduction, surface temperature is used to calculate evaporation for this presentation. Sources of surface temperature are readily available online. They include national weather and meteorology organizations such as Australian Government Bureau of Meteorology, National Oceanic Atmospheric Administration, and Canadian Climate Normals-Canadian Government.

\section{Methods}

The main concept is that annual average evaporation at the surface of the earth is measured; it is equal to annual precipitation. Therefore, if a mathematical equation correlating evaporation at a given location and annual average evaporation can be established, then meteorological records and measurements are unnecessary. The mathematical correlation is summarized in equation (21). The equation is derived based on the physics of the earth and representative scale-up of the measured world average surface temperature and evaporation. Validation of the equation is presented under Results. Derivation of the equation is divided into three stages. Stage one covers basic thermodynamics of the earth, stage two utilizes Beer-Lambert Law equation to model radiative energy exchanged with the atmosphere, and the third and last stage applies energy exchange relationships between the atmosphere and the surface of the earth.

\subsection{Thermodynamics}

The earth's subsystems that exchange solar radiation include atmosphere, surface water, and land. Land has a small thermal capacity and can be neglected. While the solar energy exchanged with surface water is thermal, or enthalpy, in nature, the energy exchanged with the atmosphere is thermal and potential energy. When the atmosphere absorbs solar heat, it rises against gravity and expands into the surrounding outer space that has negligible mass and pressure. Air expansion ceases at equilibrium. Seasonal variations affect this equilibrium because the distance between the earth and the sun varies. The axial tilt of the earth alters the energy exchanged with the geographic northern and southern hemispheres. Therefore, thermodynamic transformations must result from the motion of the earth around the sun, and the atmosphere and surface water must 
exchange energy with seasonal variations. Surface evaporation varies as a consequence.

Because the surrounding outer space has negligible mass, the potential energy and enthalpy of the atmosphere cannot be exchanged with outer space. Only radiation may be exchanged with outer space. Therefore, variation in the energy of the atmosphere can only be exchanged with the surface and the following must be valid:

$$
\begin{gathered}
\Delta E_{a}+\Delta Q_{s}=0 \\
E_{e}=E_{a}+Q_{s}=C_{1}
\end{gathered}
$$

where

$E_{a}=$ Energy of the atmosphere (enthalpy and potential energy), J.

$Q_{s}=$ Surface energy (enthalpy or heat), J.

$E_{e}=$ Energy of the atmosphere and surface combined, J.

$C_{1}=$ Constant of integration, $\mathrm{J}$.

The solar energy absorbed by the atmosphere and surface, $E_{e}$, is equal to the latent heat of surface evaporation based on observations: At the conclusion of a full revolution of the earth around the sun, variation in the energy of the surface and atmosphere are negligible for it is a repeatable cycle. The only observed change is water evaporation and its subsequent condensation as precipitation. Therefore

$$
E_{e}=E L_{v}
$$

where

$E_{e}=$ Annual rate of solar heat absorbed by the atmosphere and surface, $\mathrm{J} \cdot \mathrm{yr}^{-1}$.

$E=$ Annual rate of surface evaporation, which is equal to precipitation, $\mathrm{kg} \cdot \mathrm{yr}^{-1}$

$L_{v}=$ Latent heat of water evaporation, $2.46 \times 10^{6} \mathrm{~J} \cdot \mathrm{kg}^{-1}$.

The solar energy absorbed, $E_{e}$, can be calculated. It is approximately equal to the latent heat of condensing $2.61 \times 365=953 \mathrm{~mm}$ of rain annually [18]. This is equivalent to

$$
\begin{aligned}
E_{e} & =953 \mathrm{~mm} \times 1.0 \mathrm{~kg} \cdot \mathrm{mm}^{-1} \cdot \mathrm{yr}^{-1} \cdot \mathrm{m}^{-2} \times 5.1 \times 10^{14} \mathrm{~m}^{2} \times 2.46 \times 10^{6} \mathrm{~J} \cdot \mathrm{kg}^{-1} \\
& =1.20 \times 10^{24} \mathrm{~J} \cdot \mathrm{yr}^{-1}
\end{aligned}
$$

where $5.1 \times 10^{14}$ is the total surface area of the earth measured in $\mathrm{m}^{2}$.

\subsection{Beer-Lambert Representation}

The solar heat absorbed by the earth raises the atmosphere (air and clouds) to its current position and maintains present average surface temperature. The energy absorbed by the atmosphere is enthalpy and potential energy, whereas the surface gains solar energy as heat. Because the temperature of the sun is considerably greater than the temperature of the earth, radiation from the earth to the sun may be neglected. The net incident solar radiation may thus be assumed to be absorbed by the side of the earth's sphere facing the sun. The other side radiates 
heat to outer space. Using Beer-Lambert Law equation, the radiative energy absorbed by the atmosphere and surface are

$$
\begin{gathered}
E_{a r}=(1-f) I A_{c}\left[1-\mathrm{e}^{-\tau}\right] \\
Q_{s}=(1-f) I A_{c}\left[\mathrm{e}^{-\tau}\right]-\varepsilon A_{s} \sigma T_{s}^{4} / 2 \\
\tau=a Z_{t}
\end{gathered}
$$

where

$E_{a r}=$ Rate of radiative solar energy absorbed by the atmosphere, W.

$Q_{s}=$ Rate of radiative solar energy absorbed by the surface, $\mathrm{W}$.

$f=$ A factor that accounts for the reflected solar energy by the earth, dimensionless.

$I=$ Solar Constant, $1.368 \times 10^{3} \mathrm{~W} \cdot \mathrm{m}^{-2}$.

$A_{c}=$ Earth's circle area as viewed from the sun, $\pi\left(R_{e}+Z\right)^{2} \approx 1.28 \times 10^{14} \mathrm{~m}^{2}$.

$\tau=$ Average optical depth of the atmosphere, dimensionless.

$\varepsilon=$ Emissivity of the surface, dimensionless, approximately equal to unity.

$A_{s}=$ Earth's surface area, $4 \pi R_{e}^{2} \approx 5.1 \times 10^{14} \mathrm{~m}^{2}$.

$\sigma=$ Stefan-Boltzmann Constant, $5.67 \times 10^{-8}, \mathrm{~W} \cdot \mathrm{m}^{-2} \cdot \mathrm{K}^{-4}$.

$T_{s}=$ Surface temperature, $\mathrm{K}$.

$a=$ Absorption coefficient of solar radiation by the atmosphere (air and clouds), $\mathrm{km}^{-1}$.

$Z_{t}=$ Average distance traveled by solar radiation in the atmosphere, $\mathrm{km}$.

$R_{e}=$ Earth's radius, $6.38 \times 10^{6} \mathrm{~m}$.

The radiative energy absorbed by the atmosphere, $E_{a r}$, can be determined from data available. It is approximately equal to one third of the total solar energy absorbed by the atmosphere and surface, $E_{e}$, based on [19]. The radiative energy exchanged with the atmosphere is thus equal to $E_{a r}=E_{e} / 3=1.20 \times 10^{24} \mathrm{~J} \cdot \mathrm{yr}^{-1} / 3=4.0 \times 10^{23} \mathrm{~J} \cdot \mathrm{yr}^{-1}\left(1.27 \times 10^{16} \mathrm{~W}\right)$. The measured value of the factor, $f$, is approximately equal to 0.30 [20]. From Equation (5), the average value of the optical depth of the atmosphere is equal to $\tau=$ 0.107. Also, this value of optical depth can be calculated by trial and error solution of Equations (4), (5), and (6) for the entire surface at a surface temperature $T_{s}=286.70 \mathrm{~K}$.

Figure 1 illustrates the earth viewed from the sun as a disc, and Figure 2 is a cross section of the earth with a perpendicular plane through the noon line A-A. In Figure 3, a cross section of the earth with a perpendicular plane through the line B-B at arbitrary latitude is presented. As Figure 1 reveals, the distance traveled by sunrays along any diameter is the same, and the average distance traveled is equal to that at noon. Figure 2 illustrates incident sunrays at noon for arbitrary latitude $\theta$. The average distance traveled, $Z_{t}$, is equal to that calculated at noon, Figure 2, as follows:

$$
Z_{t}=(1 / \pi) \int_{-\pi / 2}^{+\pi / 2} Z_{n}(\theta) \mathrm{d} \theta
$$




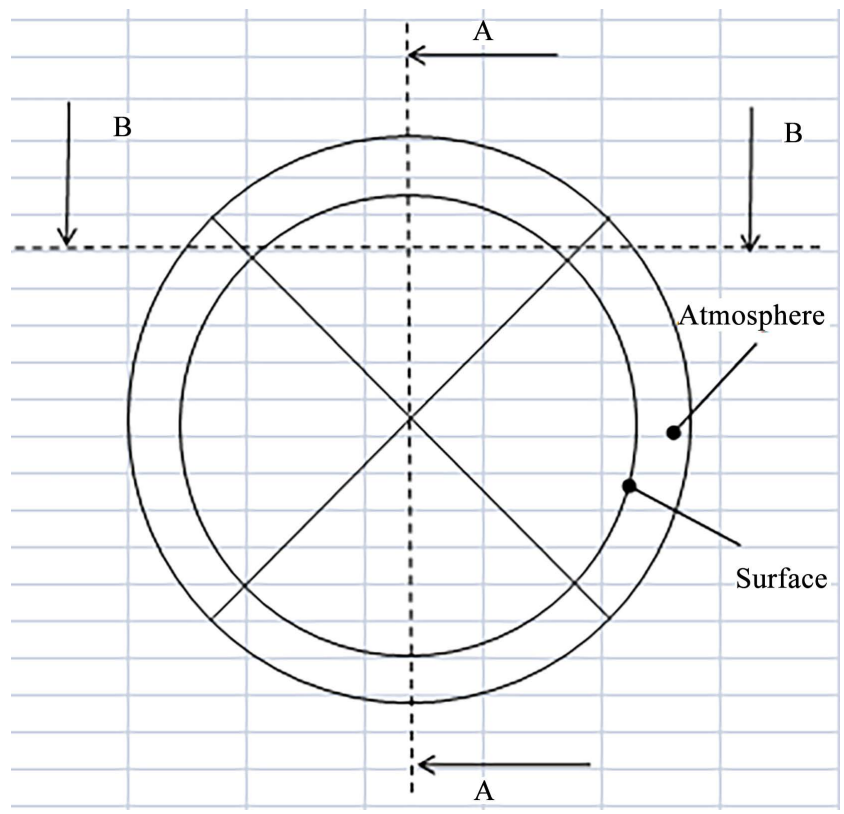

Figure 1. The earth's circle area, $A_{c}$, as viewed from the sun.

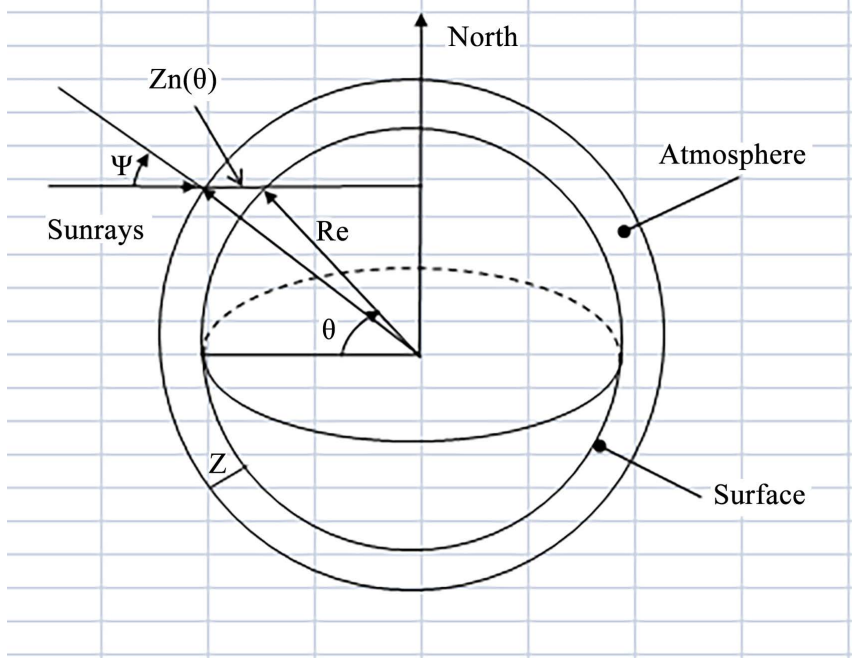

Figure 2. Cross section, A-A, viewed from the right showing the earth's circle at noon and the incident sunrays on an arbitrary latitude $\theta$.

where $\theta$ is arbitrary latitude and $Z_{n}(\theta)$ is the distance traveled by sunrays in the atmosphere at noon for the arbitrary latitude

$$
Z_{n}(\theta)=\left(R_{e}+Z\right) \cos (\psi)-R_{e} \cos (\theta)
$$

where $Z$ is the height of the atmosphere, approximately equal to the average height of the mesopause, $96 \mathrm{~km}$ [21]. From Figure 2 and Figure 3, the average distance traveled by sunrays, $Z_{t}(\theta)$, at the arbitrary latitude, $\theta$, is equal to

$$
Z_{t}(\theta)=(1 / \pi) \int_{-\pi / 2}^{+\pi / 2} Z(\phi) \mathrm{d} \phi
$$

where 


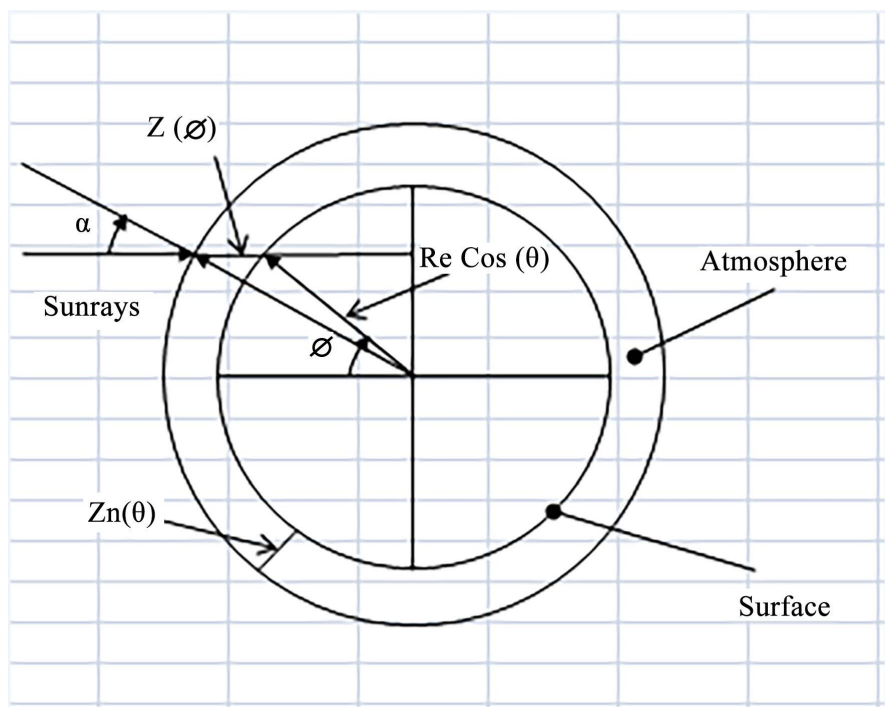

Figure 3. Cross section, B-B, viewed from the top showing the earth's longitude circle and the incident sunrays on an arbitrary longitude $\phi$.

$$
Z(\phi)=\left[R_{e} \cos (\theta)+Z_{n}(\theta)\right] \cos (\alpha)-R_{e} \cos (\theta) \cos (\phi)
$$

In Table 1, the average distance traveled by sunrays in the atmosphere, $Z_{t}(\theta)$, is tabulated. The table reveals that the average distance traveled at noon, $Z_{t}(\theta)$, for $\theta=0$ is $223.2 \mathrm{~km}$. Based on Equation (7), the average coefficient of solar energy absorption by the atmosphere $a=0.107 / 223.2=0.00048 \mathrm{~km}^{-1}$, which can be reasonably used for all other latitudes. The optical depth of the atmosphere for other latitudes is then determined by multiplying $Z_{t}(\theta)$ by 0.00048 , they are presented in Table 1 .

\subsection{Energy Exchange}

From Equations (5) and (6)

$$
\Delta Q_{s}=-\Delta E_{a r}=-(1-f) I A_{c} \mathrm{e}^{-\tau} \Delta \tau
$$

Not considered in Equation (12) is variation in the radiation term ( $\varepsilon A_{s} \sigma T_{s}^{4} / 2$ ) of Equation (6). The reason is that, unlike solid surfaces, surface water has negligible thermal conductivity, and the value of this term is controlled by convention heat transfer of surface water. The convection heat transfer coefficient does not vary tangibly with the observed surface temperature variation, and variation in this radiation term may be neglected. Equation (12) indicates that variation in the optical depth of the atmosphere induces a thermodynamic transformation where energy is exchanged between the atmosphere and surface. For the scenario where energy is transferred from the cold atmosphere to the warm surface, the external energy required is available; it is equal to the variation in the potential energy of the atmosphere and the laws of thermodynamics are thus satisfied. For a given latitude, $\theta$, the solar heat exchanged with the surface follows based on Equation (12): 
Table 1. Latitude optical depth and solar energy. The solar energy absorbed by the atmosphere and the incident solar energy on the surface are for a plane perpendicular to the incident solar radiation.

\begin{tabular}{|c|c|c|c|c|c|}
\hline $\begin{array}{c}\text { Latitude, } \\
\text { degrees }\end{array}$ & $Z_{t}, \mathrm{~km}$ & $Z_{t}(\theta), \mathrm{km}$ & $\begin{array}{c}\text { Optical } \\
\text { depth }\end{array}$ & $\begin{array}{c}\text { Solar energy } \\
\text { absorbed by atm., } \\
\mathrm{W} \cdot \mathrm{m}^{-2}\end{array}$ & $\begin{array}{c}\text { Solar energy to } \\
\text { surface, } \\
\mathrm{W} \cdot \mathrm{m}^{-2}\end{array}$ \\
\hline 0 & 96.0 & 223.2 & 0.107 & 97.3 & 860.3 \\
\hline 5 & 96.4 & 223.9 & 0.107 & 97.6 & 860.0 \\
\hline 10 & 97.5 & 225.8 & 0.108 & 98.4 & 859.2 \\
\hline 15 & 99.3 & 228.8 & 0.110 & 99.6 & 858.0 \\
\hline 20 & 102.1 & 233.5 & 0.112 & 101.5 & 856.1 \\
\hline 25 & 105.8 & 239.6 & 0.115 & 104.0 & 853.6 \\
\hline 30 & 110.6 & 247.4 & 0.119 & 107.2 & 850.4 \\
\hline 35 & 116.8 & 257.3 & 0.124 & 111.3 & 846.3 \\
\hline 40 & 124.7 & 269.7 & 0.129 & 116.3 & 841.3 \\
\hline 45 & 134.8 & 285.0 & 0.137 & 122.4 & 835.2 \\
\hline 50 & 147.8 & 304.1 & 0.146 & 130.1 & 827.5 \\
\hline 55 & 164.9 & 328.3 & 0.158 & 139.6 & 818.0 \\
\hline 60 & 187.9 & 359.1 & 0.172 & 151.6 & 806.0 \\
\hline 65 & 219.9 & 399.5 & 0.192 & 167.1 & 790.5 \\
\hline 70 & 266.5 & 454.0 & 0.218 & 187.5 & 770.1 \\
\hline 75 & 338.9 & 530.6 & 0.255 & 215.3 & 742.3 \\
\hline 80 & 461.0 & 644.3 & 0.309 & 254.7 & 702.9 \\
\hline 85 & 686.0 & 823.1 & 0.395 & 312.5 & 645.1 \\
\hline 90 & 1110.1 & 1110.1 & 0.533 & 395.6 & 562.0 \\
\hline
\end{tabular}

$$
\Delta Q_{s}(\theta)=-(1-f) I A_{c}(\theta) \mathrm{e}^{-\tau(\theta)} \Delta \tau(\theta)
$$

where $\Delta Q_{s}(\theta)$ is variation in the rate of energy exchanged with the surface at the latitude in consideration, $W ; A_{c}(\theta)$ is the surface area perpendicular to solar radiation, $\mathrm{m}^{2} ; \tau(\theta)$ is the average optical depth of the atmosphere at the latitude in consideration, dimensionless; and $\theta$ is latitude in degrees. Because variation in the total rate of energy exchanged with the surface, $\Delta Q_{s}$, is known, then variation in the rate of energy exchanged with the surface at any latitude, $\Delta Q_{s}(\theta)$, can be calculated from Equations (12) and (13)

$$
\Delta Q_{s}(\theta)=\Delta Q_{s} \times[\Delta \tau(\theta) / \Delta \tau] \mathrm{e}^{-[\tau(\theta)-\tau]} \times A_{c}(\theta) / A_{c}
$$

Seasonal variation occurs infinitesimally with time and the height of the atmosphere varies infinitesimally as well. The distance traveled by solar radiation is variable and the optical depth of the atmosphere varies as a consequence. Because the diameter of the atmosphere is large, its circumference can be assumed to be a straight line in a small area. Similarities between triangles following small 
variation in the height of the atmosphere, Figure 2 and Figure 3, reveal that $\Delta Z(\phi) / Z(\phi) \approx \Delta Z_{n}(\theta) / Z_{n}(\theta) \approx \Delta Z / Z$ and $\Delta Z(\phi) \times Z_{n}(\theta) \approx \Delta Z_{n}(\theta) \times Z(\phi)$. Both sides of this last equality can be multiplied by $(1 / \pi)^{2}$ and double integrated with respect to $\theta$ and $\phi$, in a similar fashion to equations (8) and (10). Keeping in mind that the functions and variables are separable, the result of the double integration is $\Delta Z_{t}(\theta) / Z_{t}(\theta) \approx \Delta Z_{t} / Z_{t}$. If the numerators and denominators are multiplied by the absorption coefficient of solar radiation, $a$, then $\Delta \tau(\theta) / \tau(\theta) \approx \Delta \tau / \tau, \Delta \tau(\theta) / \Delta \tau \approx \tau(\theta) / \tau$, and Equation (14) simplifies

$$
\Delta Q_{s}(\theta)=\Delta Q_{s} \times[\tau(\theta) / \tau] \mathrm{e}^{-[\tau(\theta)-\tau]} \times A_{c}(\theta) / A_{c}
$$

Variation in the rate of energy exchanged with the surface at a given latitude, $\Delta Q_{s}(\theta)$, can be used to calculate latitude temperature change

$$
\begin{aligned}
& \Delta T_{s}(\theta)=\Delta Q_{s}(\theta) /\left[M(\theta) C p_{a}\right] \\
& M(\theta)=E(\theta) /\left[W_{s}(\theta)-W_{t}(\theta)\right]
\end{aligned}
$$

where

$\Delta T_{s}(\theta)=$ Variation in latitude surface temperature, $\mathrm{K}$.

$M(\theta)=$ Latitude flow rate of the circulated dry air, $\mathrm{kg} \cdot \mathrm{yr}^{-1}$.

$C p_{a}=$ Specific heat of air, $\mathrm{J} \cdot \mathrm{kg}^{-1} \cdot \mathrm{K}^{-1}$.

$E(\theta)=$ Latitude rate of surface evaporation, $\mathrm{kg} \cdot \mathrm{yr}^{-1}$.

$W_{s}(\theta)=$ Latitude water vapor mixing ratio, $\mathrm{kg}$ water per $\mathrm{kg}$ dry air.

$W_{t}(\theta)=$ Latitude water vapor mixing ratio at the tropopause, $0.0 \mathrm{~kg}$ water per kg dry air.

Equations (15), (16), and (17) yield

$$
E(\theta)=\left[\Delta T_{s} / \Delta T_{s}(\theta)\right] \times[\tau(\theta) / \tau] \mathrm{e}^{-[\tau(\theta)-\tau]} \times E \times W_{s}(\theta) / W_{s} \times A_{c}(\theta) / A_{c}
$$

where $E$ is a known surface water evaporation at a known latitude, and the measured world average precipitation of the entire surface of the earth will be used for $E$; $\Delta T_{s}$ is variation in the world average surface temperature, $\mathrm{K}$; and $W_{s}$ is the world average water vapor mixing ratio, kg water per kg dry air. These world average meteorological parameters are measured or available and can thus be used as pilot data for scale-up. Therefore evaporation at any latitude can be determined by measuring or calculating latitude surface temperature, $T_{s}(\theta)$. The rest of the variables are known from the motion of the earth around the sun and Table 1.

\section{Results}

The solution of Equation (18) requires obtaining the latitude at which world average surface temperature and evaporation occur. This latitude can be determined by computing the average optical depth for a hemisphere $\tau_{h}$

$$
\tau_{h}=\left(1 / A_{h}\right) \int_{0}^{A_{h}} \tau(\theta) \mathrm{d} A_{h}
$$

where $A_{h}$ is surface area of half hemisphere $\left(\pi R_{e}^{2}\right)$ that observes solar radia- 
tion. Equation (19) can be simplified for finite element analysis

$$
\tau_{h}=\sum_{\theta=0}^{\theta=\theta_{f}} \tau(\theta) \cos (\theta) \mathrm{d} \theta
$$

The upper limit of the summation, $\theta_{f}$, is the latitude where surface water exists. It is approximately equal to 70 degrees. Thereafter, the surface is assumed to be covered with Arctic and Antarctic ice. Integration of Equation (20) yields to $\tau_{h}=0.128$ based on Table 1 . From this table, the world average meteorological parameters are equal to those measured at approximate latitude of $40^{\circ}$. Therefore, the latitude of $40^{\circ}$ can be used for evaporation scale-up, as pilot latitude at which world average surface temperature and evaporation are known and available.

Equation (18) gives latitude surface evaporation, $E(\theta)$, if the angle $\theta$ and surface temperature change, $\Delta T_{s}(\theta)$, of the latitude in consideration are known. On the other hand, the world average values of $E, \Delta T_{s}$, and $W_{s}$ are a result of solar energy exchanged. If the solar radiation is imagined to cease, surface air temperature approaches zero absolute. At steady state when surface evaporation, $E$, is equal to the observed average value, variation of surface air temperature, $\Delta T_{s}$, measures average surface temperature rise with respect to zero absolute. The ratio, $\Delta T_{s} / \Delta T_{s}(\theta)$, can thus be replaced by $T_{s} / T_{s}(\theta)$, where the values of the temperature are in degrees Kelvin. The ratio $W_{s}(\theta) / W_{s}$ is reasonably equal to the ratio of absolute humidity at saturation. This ratio can be determined if $T_{s}(\theta)$ is known, for the average surface temperature $T_{s}$ is available. The world average evaporation, $\mathrm{E}$, calculated at $40^{\circ}$ latitude is available in the literature; it is equal to the annual precipitation, about $953 \mathrm{~mm}$ annually [18]. Equation (18) simplifies

$$
\begin{aligned}
E(\theta)= & {\left[\left\{T_{s}(40)+273.2\right\} /\left\{T_{s}(\theta)+273.2\right\}\right] \times[\tau(\theta) / \tau(40)] \mathrm{e}^{-[\tau(\theta)-\tau(40)]} } \\
& \times(953 / 365) \times\left[W_{s}(\theta) / W_{s}(40)\right] \times[\cos (\theta) / \cos (40)]
\end{aligned}
$$

In Equation (21), the ratio $A_{c}(\theta) / A_{c}(40)$ is replaced with its equivalent $\cos (\theta) / \cos (40)$. The values of $T_{s}$ and $T_{s}(\theta)$ are now in ${ }^{\circ} \mathrm{C}$. Open water evaporation, $E(\theta)$, is in $\mathrm{mm} \cdot \mathrm{day}^{-1}$.

Calculation steps of open water evaporation follow: Step one: given day of the year, $d$, where January $1^{\text {st }}$ is day 1 , calculate the declination angle, $\delta$, in degrees, $\delta=\sin ^{-1}\left[\sin \left(23.5^{\circ}\right) \sin \{(360 / 365)(d-81)\}\right]$. Step two: calculate the instantaneous latitude $\theta=$ geographic latitude- $\delta$. In the southern hemisphere the geographic latitude is negative. Step three: read from Table 1 the optical depth, $\tau(\theta)$, for the calculated instantaneous latitude $\theta$. Interpolate/extrapolate as required. Step four: solve Equation (21) for open water evaporation, $E(\theta)$, in $\mathrm{mm} \cdot \mathrm{day}^{-1}$. On monthly basis, use for, $d$, average day of the month for simplicity and multiply by the number of days of the month in consideration. For annual evaporation multiply average daily evaporation by 365 . Justification for using the pilot data for average surface temperature, $T_{s}(40)$, is explained under the Discussion section. Example: 
Lake Okanagan, Canada, average evaporation for the month of October: $d$ $=288.5$; number of days $=31$; latitude $=49.5^{\circ} \mathrm{N} ; T_{s}(40)=14.9^{\circ} \mathrm{C}$; declination angle $=-9.8^{\circ} ; \theta=49.5+9.8=59.3^{\circ} \mathrm{N} ; T_{s}(\theta)=10.2^{\circ} \mathrm{C}$, Kelowna; from Table 1 $\tau(\theta)=0.171, \tau(40)=0.129$; at saturation $W_{s}(\theta) / W_{s}(40)=0.71 ; E(\theta)=1.6$ $\mathrm{mm} \cdot$ day $^{-1} ; E(\theta)=1.6 \times 31=50 \mathrm{~mm}$ for October. Observed open water evaporation is unavailable, observed class A pan evaporation is $70 \mathrm{~mm}$; estimated pan coefficient $=50 / 70=0.71$. Similarly, brine evaporation can be calculated by knowing the total dissolved solids. These reduce vapor pressure, which can be obtained and $W_{s}(\theta)$ determined. Evaporation from brine can be calculated following the same procedure. Calculation of monthly evaporation for sample locations is presented in Table 2 .

\section{Discussion}

Evaporation calculation and projection in a warming world are important at the societal level. Presently, there are no low cost and accurate methods at the same time for calculating evaporation. Background Information and Data sections present examples where calculation of evaporation with accuracy is determined. It is complex and requires substantial resources. The inconveniences and limitations of the present methods are inherent to considering surface evaporation as a function of ambient conditions. Meteorological data and measurements are thus required. The work presented in this manuscript reveals that evaporation is a function of the solar heat exchanged with the surface, and can be addressed as a

Table 2. Calculated and actual observed open water evaporation, $\mathrm{mm} \cdot \mathrm{day}^{-1}$.

\begin{tabular}{|c|c|c|c|c|c|c|c|c|}
\hline \multirow[t]{3}{*}{$\begin{array}{c}\text { Description/ } \\
\text { Location }\end{array}$} & \multicolumn{4}{|c|}{ Dead Sea, Jordan } & \multirow{2}{*}{\multicolumn{2}{|c|}{$\begin{array}{c}\text { Melbourne, } \\
\text { Australia } \\
\text { Specific gravity } 1.00\end{array}$}} & \multirow{2}{*}{\multicolumn{2}{|c|}{$\begin{array}{c}\text { Lake IJssel, } \\
\text { Netherlands } \\
\text { Specific gravity } 1.00\end{array}$}} \\
\hline & \multicolumn{2}{|c|}{ Specific gravity 1.00} & \multicolumn{2}{|c|}{ Specific gravity 1.26} & & & & \\
\hline & Calculated & Observed & Calculated & Observed & Calculated & Observed & Calculated & Observed \\
\hline January & 2.56 & 3.24 & 1.34 & 1.34 & 5.56 & 6.45 & 0.66 & 0.36 \\
\hline February & 3.05 & 3.86 & 1.62 & 1.73 & 5.39 & 5.36 & 0.81 & 0.55 \\
\hline March & 4.02 & 4.97 & 2.17 & 2.35 & 4.58 & 4.84 & 1.17 & 0.94 \\
\hline April & 5.27 & 7.12 & 2.89 & 3.98 & 3.33 & 2.67 & 1.59 & 2.00 \\
\hline May & 6.93 & 8.95 & 3.87 & 5.12 & 2.46 & 1.71 & 2.02 & 2.97 \\
\hline June & 8.68 & 10.12 & 4.90 & 6.07 & 1.94 & 1.00 & 2.61 & 3.45 \\
\hline July & 9.92 & 10.10 & 5.65 & 6.07 & 1.91 & 1.61 & 2.67 & 3.05 \\
\hline August & 9.63 & 10.19 & 5.48 & 5.70 & 2.32 & 1.94 & 2.79 & 2.58 \\
\hline September & 8.19 & 8.71 & 4.63 & 4.68 & 2.94 & 2.67 & 2.22 & 1.66 \\
\hline October & 5.87 & 6.68 & 3.26 & 3.35 & 3.63 & 4.03 & 1.71 & 0.92 \\
\hline November & 3.52 & 4.84 & 1.90 & 2.16 & 4.29 & 5.83 & 0.89 & 0.55 \\
\hline December & 2.74 & 3.48 & 1.46 & 1.47 & 4.88 & 5.65 & 0.63 & 0.35 \\
\hline Annual & 5.87 & 6.87 & 3.26 & 3.67 & 3.60 & 3.65 & 1.65 & 1.62 \\
\hline
\end{tabular}


climate parameter instead. No meteorological records are thus required. This is a major difference between the methods that can yield to a low cost and reasonably accurate methodology for calculating evaporation. Additionally, the proposed method can be used to project evaporation with climate change, whereas the existing methods cannot.

Unlike the existing methods of calculating evaporation, the method used in this work adheres to the scale-up methodologies. All latitudes are in fact circular, and those in consideration between $0^{\circ}$ and $70^{\circ}$ are similar in having atmosphere, surface water, land, outer space, solar radiation, and gravity. They are smaller earths and can be scaled-up from one another. Therefore, dimensionless scale-up groups are derived and used in Equation (21). By far the most complex similitude relationship to establish is the geographic one. Land albedo, elevation, and thermal properties can be different. Theoretical and empirical relationships are available in the literature, example [22], and can be used to calculate surface temperature by knowing the intensity of the incident solar radiation, land albedo, and land thermal properties. Adjustment for elevation can be computed as well and surface temperature at any geographic location obtained. However, if surface temperature of the location in consideration is available, then surface temperature calculation is not required. Land elevation, albedo, thermal properties, and intensity of the incident solar radiation are unnecessary as well. The only requirement needed is to establish a "geographic" similarity using pilot surface temperature of similar geographic locations, which are available, however these are discrete values. Accordingly, Equation (21) is derived based on the physics of the earth and similitude between latitudes. For this equation, location surface temperature, $T_{s}(\theta)$, and the temperature of a similar pilot geographic location, $T_{s}\left(40^{\circ}\right)$, are the only requirements.

The measured pilot temperature values of $T_{s}\left(40^{\circ}\right)$ for geographic similarity are average surface temperatures at approximate latitude of $40^{\circ}$ as determined under Results. At this latitude, the world average precipitation is also measured and it is equal to the world average evaporation, E, used in Equation (21). Although the measured world average precipitation is equal to average evaporation, they are not necessarily equal at a given latitude. For instance, in arid locations precipitation is negligible but evaporation is high. The evaporation calculated by Equation (21) is a "potential" evaporation of an imaginary water body having constant water inventory at the location in consideration.

Because average surface temperature is used as pilot data for evaporation scale-up, selection of this temperature, $T_{s}(40)$, in Equation (21) is important. This selection is based on "geographic" similarities with the locations where evaporation calculation is desired. If the location is close to sea water, Sea Surface Mean Temperature of $16.1^{\circ} \mathrm{C}$ should be used for average surface temperature $T_{s}(40)$. If the location is in remote area inland where sea water has minimal to no effect, Land Surface Mean Temperature of $8.5^{\circ} \mathrm{C}$ should be used instead. The selection is based on the weighted average surface temperatures reported by 
[23]. For locations in between, the Combined Mean Surface Temperature of $14.9^{\circ} \mathrm{C}$ and $13.3^{\circ} \mathrm{C}$ should be used for the northern and southern hemispheres respectively [24].

\section{Conclusions}

Table 2 presents sample locations where the observed evaporation is determined by using the evaporation pan method. The calculated annual evaporation is practically equal to the observed annual evaporation for Melbourne and Lake Ijssel. They differ on a monthly basis, and this is anticipated for the mass of water in evaporation test pans is much smaller than those of water bodies. The impact of local ambient conditions is relevant for these pans. Consequently, the pans evaporate less than actual during the cold months and more than actual during the hot months. For the Dead Sea, the observed evaporation is slightly greater than the calculated evaporation. This is expected, because the used pan coefficient of 0.74 by [12] appears to be slightly high. Reference [11] recommends 0.60 - 0.70. Using the calculation steps presented under Results, evaporation around the world can be calculated, including areas that experience monsoons and tropical cyclones. Because the observed open water evaporation is generally unavailable for cost considerations, pan coefficient is estimated from measured class A pan evaporation or equal data. The calculated annual pan coefficient for a large number of locations is between 0.55 and 0.75 . This range is well within the observed range of 0.35 and 0.85 [6]. Based on these agreements with observations, it is reasonable to conclude that the derived Equation (21) can yield good values of open water evaporation and that evaporation can be treated as a climate parameter. In addition the scale-up methodology appears to apply for the earth system as well. The equation can be used to project future evaporation because temperature trend is available in the reports of the Intergovernmental Panel on Climate Change.

Evaporation varies with weather departure from average conditions, and evaporation departure can be calculated with this method, including maximum and minimum daily evaporation. However, the long-term average evaporation varies with the seasons. As a result, monthly evaporation maps are prepared around the world, which suggests that evaporation is a climate parameter based on observations as well.

It should be noted that Equation (21) does not account for the impact of variation in the distance between the earth and the sun because it is small compared with the effect of the earth's axial tilt. On an annual basis, the calculated evaporation by Equation (21) does not require correction for distance variation. However, correction is required on a monthly basis. The correction is $+3.8 \%$ for December and $-3.8 \%$ for June. A linear interpolation may be used for the months in between. This correction is based on a maximum total variation in the solar constant of about $7.5 \%$ with respect to its average value according to [25]. The accuracy of the calculated evaporation by Equation (21) after correction for 
distance variation between the sun and the earth is $\pm 8.8 \%$ based on [18]. This publication reveals that the measured global mean daily precipitation rate, $E$, is $2.61 \pm 0.23 \mathrm{~mm} \cdot \mathrm{day}^{-1}$.

Finally, the values used for the pilot average surface temperature $T_{s}(40)$ in the calculations are only those mentioned under the Discussion section. They are limited and discrete values. If the values can be interpolated or extrapolated based on geography or other considerations, open water evaporation could be calculated practically accurately. As of now, using such a procedure cannot be justified based on the available literature. Therefore, room for improvement exists.

\section{Acknowledgements}

Thanks to the team of the Journal of Water Resources and Protection for their review and comments. It is gratefully acknowledged for handling the manuscript. The time and effort of those who contributed directly or indirectly to this work are appreciated.

\section{Conflicts of Interest}

The authors declare no conflicts of interest regarding the publication of this paper.

\section{References}

[1] SFBCDC (2005) Salt Ponds. Staff Report, San Francisco Bay Conservation and Development Commission. http://www.bcdc.ca.gov/planning/reports/SaltPonds_Jun2005.pdf

[2] Berube, D., Diebel, P., Rollin, A. and Stark, T.D. (2007) Massive Mining Evaporation Ponds Constructed in Chilean Desert. Geosynthetics, IFAI Publications, 27-33. https://geosyntheticsmagazine.com/?s=Berube\%2C+D.\%2C+Diebel\%2C+P.\%2C

[3] Bond, R. and Veerapaneni, S. (2003) Zero Liquid Discharge for Inland Desalination. Project 3010, AWWA Research Foundation, Denver Colorado. http://www.waterrf.org/sites/Search/Pages/results.aspx?k=Zero\%20Discharge http://www.waterrf.org/PublicReportLibrary/91190.pdf

[4] Brandhuber, P., Cerone, J., Kwan, P., Moore, E.L. and Vieira, A. (2007) A Look at Conventional and Emerging Brine Disposal and Waste Minimization Technologies. HDR Waterscapes, 19, 7-10. https://www.hdrinc.com

[5] Tuttle, R.W. and Highfill, G. (1982) Ponds-Planning, Design, Construction. Agriculture Handbook 590, United States Department of Agriculture. https://www.nrcs.usda.gov/Internet/FSE_DOCUMENTS/nrcs144p2_030362.pdf

[6] Allen, R.G., Pereira, L.S., Raes, D. and Smith, M. (1990) Crop Evapotranspiration (Guidelines for Computing Crop Water Requirements)_FAO Irrigation and Drainage Paper 56, 79-98. http://www.fao.org/docrep/X0490E/x0490e00.htm

[7] Penman, H.L. (1948) Natural Evaporation from Open Water, Bare Soil and Grass. Proceedings of the Royal Society A Mathematical, Physical, and Engineering Sciences, 193, 120-145. https://doi.org/10.1098/rspa.1948.0037 
[8] Priestley, C.H.B. and Taylor, R.J. (1972) On the Assessment of the Surface Heat Flux and Evaporation Using Large-Scale Parameters. Monthly Weather Review, 100, 81-92. https://doi.org/10.1175/1520-0493(1972)100<0081:OTAOSH >2.3.CO;2

[9] Zotarelli, L., Dukes, M.D., Romero, C.C., Migliaccio, K.W. and Morgan, K.T. (2010) Step by Step Calculation of the Penman-Monteith Evapotranspiration (FAO-56 Method). Doc. AE459, University of Florida. https://edis.ifas.ufl.edu/pdffiles/AE/AE45900.pdf

[10] Djaman, K., Irmak, S., Kabenge, I. and Futakuchi, K. (2016) Evaluation of FAO-56 Penman-Monteith Model with Limited Data and the Valiantzas Models for Estimating Grass-Reference Evapotranspiration in Sahelian Conditions. Journal of Irrigation and Drainage Engineering, 142, Article ID: 04016044.

[11] Butts, D. (1980) Theory and Practice of Extracting Minerals from Brine. Vol. 1, Solar Ponds, Great Salt Lake Minerals and Chemicals Corporation, Ogden, Utah.

[12] Coyne-Et Bellier, Tractabel Engineering and Kema (2011) Red Sea-Dead Sea Conveyance Study Program, Appendix D, Dead Sea Water Mass Balance Model. Gennevilliers Cedex, France.

http://www.waj.gov.jo/sites/en-us/Documents/RSDS\%20Project/vol1/Appendix\%20 D\%20-\%20Dead\%20Sea\%20Water\%20Mass\%20Balance\%20Model.pdf

[13] Finch, J.W. and Hall, R.L. (2001) Estimation of Open Water Evaporation, A Review of Methods. R\&D Technical Report W6-043/TR, Environment Agency, Bristol, England.

https://www.gov.uk/government/uploads/system/uploads/attachment_data/file/290 578/sw6-043-tr-e-e.pdf

[14] Schertzer, W.M. and Taylor, B. (2009) Assessment of the Capability to Compute Evaporation from Okanagan Lake, Other Mainstem Lakes and Basin Lakes and Reservoirs Using the Existing Database. WSTD Contribution No. 08-547, Environment Canada, Water Science and Technology Directorate.

http://www.obwb.ca/fileadmin/docs/okanagan_evaporation.pdf

[15] Badawi, H.A. (2009) Effect of Expected Climate Changes on Evaporation Losses from Aswan High Dam Reservoir (AHDR). Thirteenth International Water Technology Conference, IWTC 13 2009, Hurghada, Egypt. http://www.iwtc.info/2009_pdf/1-1.pdf

[16] Perry, R.H. and Green, D. (1984) Perry's Chemical Engineers Handbook, In: Kuang-Hui, L., Hendrick, C., Ness, V. and Abbott, M., Eds., Scale-Up Methods, 6th Edition, Mc Graw-Hill, New York, USA, 4-21.

[17] Braak, C. (1936) Report on Question 1, Evaporation for the Royal Netherlands Meteorological Institute, De Bilt, Netherlands. The Meeting of the Union at Edinburgh, 114. http://hydrologie.org/redbooks/a025/Potam_Q1_R4.pdf

[18] Gruber, A. and Levizzani, V. (2008) Assessment of Global Precipitation Products. WCRP-128, WMO/TD-No. 1430, World Climate Research Program, Global Energy and Water Cycle.

[19] Trenberth, K.E., Fasullo, J.T. and Kiehl, J. (2009) Earth's Global Energy Budget. Bulletin of the American Meteorological Society, 90, 311-323. https://doi.org/10.1175/2008BAMS2634.1

[20] NASA (1999) National Aeronautics Space Administration (NASA) Earth Observatory, Clouds and Radiation, by Steve Graham. http://earthobservatory.nasa.gov/Features/Clouds/

[21] She, C.Y., Chen, S., Hu, Z., Sherman, J., Vance, J.D., Vasoli, V., White, M.A., Yu, J. and Krueger, D.A. (2000) Eight-Year Climatology of Nocturnal Temperature and 
Sodium Density in Mesopause Region (80 to $105 \mathrm{~km}$ ) over Fort Collins, Co $\left(41^{\circ} \mathrm{N}\right.$ and $\left.105^{\circ} \mathrm{W}\right)$. Geophysical Research Letters, 27, 3289-3292.

[22] Vernekar, A.D. (1975) A Calculation of Normal Temperature at Earth's Surface. Journal of the Atmospheric Sciences, 32, 2067-2081. https://doi.org/10.1175/1520-0469(1975)032<2067:ACONTA>2.0.CO;2

[23] NOAA (2000) Global Mean Monthly Surface Temperature Estimates for the Base Period 1901 to 2000. National Oceanic and Atmospheric Administration (NOAA), National Climate Data Center. https://www.ncdc.noaa.gov/monitoring-references/faq/anomalies.php

[24] Jones, P.D., New, M., Parker, D.E., Martin, S. and Rigor, I.G. (1999) Surface Air Temperature and Its Changes over the Last 150 Years. Reviews of Geophysics, 37, 172-199. https://doi.org/10.1029/1999RG900002

[25] NASA (1991) National Aeronautics Space Administration Preferred Reliability Practices, Earth Orbit Reliability Heating. Guideline No. GD-AP-2301. https://ntrs.nasa.gov/archive/nasa/casi.ntrs.nasa.gov/19920003068.pdf 